\title{
Use of adrenaline for specimen fixation after endoscopic submucosal dissection
}

To judge how likely an endoscopic submucosal dissection (ESD) is to have been curative and the necessity for additional treatment, accurate histological diagnosis is critical. The resected specimen is stretched and fixed, mucosal side up, onto a rubber or cork plate, so that the mucous membrane surrounding the lesion is evenly flattened and the mucous membrane surface can be observed. The resected specimen often curls up ( $\triangleright$ Fig.1 a), so fixing of the specimen can be difficult and stressful.

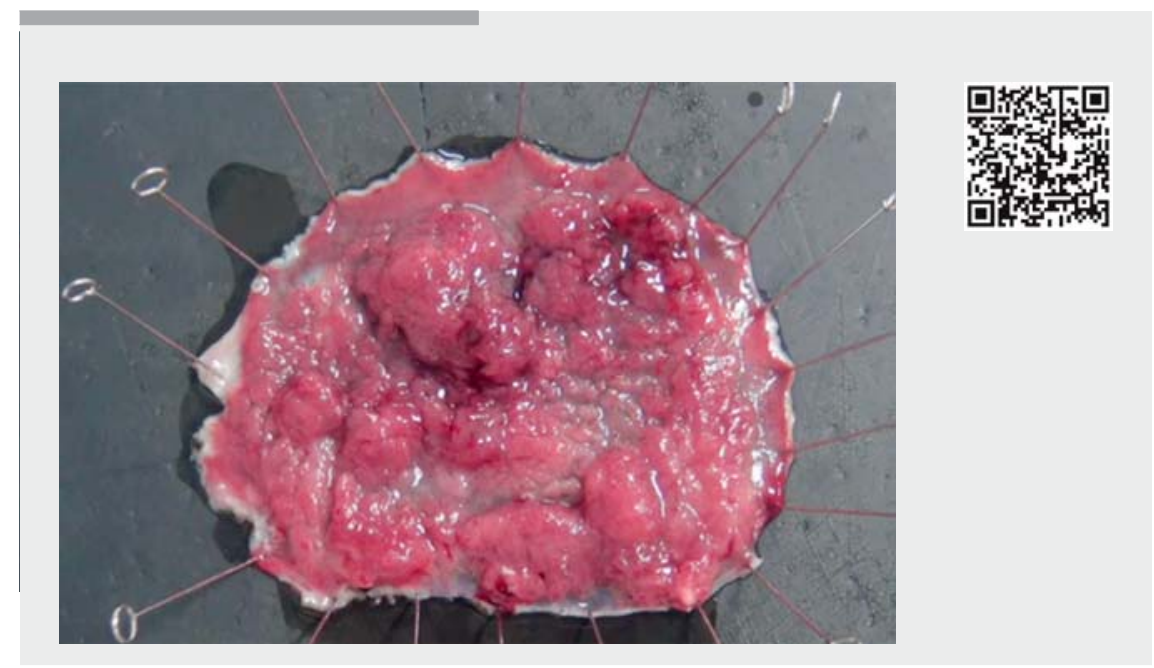

$\checkmark$ Video 1 A resected specimen after endoscopic submucosal dissection curls up, so fixing onto a plate is difficult; adrenaline is dropped onto the specimen; the specimen becomes relaxed; the resected specimen can now be easily fixed mucosal side up onto a plate.
- Video 1 shows that, when adrenaline is dropped onto the specimen, it becomes relaxed ( $\nabla$ Fig. $\mathbf{1} \mathbf{b}$ ). Adrenaline has the effect of relaxing intestinal smooth muscle and thereby makes it easier to fix the specimen onto a plate ( $\boldsymbol{F}$ Fig. $\mathbf{1} \mathbf{c}$ ).

\section{Endoscopy_UCTN_Code_TTT_1AO_2AG}

Competing interests

None

The authors

Toshihiro Nishizawa ${ }^{1,2}$, Satoshi Kinoshita ${ }^{1}$, Hideki Mori' ${ }^{1}$, Ai Fujimoto ${ }^{1}$

1 Department of Gastroenterology, National Hospital Organization Tokyo Medical Center, Tokyo, Japan

2 Department of Gastroenterology and Hepatology, International University of Health and Welfare Mita Hospital, Tokyo, Japan

Corresponding author

\section{Toshihiro Nishizawa, MD, PhD}

Department of Gastroenterology, National Hospital Organization Tokyo Medical Center, 2-5-1 Higashigaoka, Meguro-ku,

Tokyo 151-0021, Japan nisizawa@kf7.so-net.ne.jp

\section{Bibliography}

DOI https://doi.org/10.1055/a-0866-9302

Published online: 30.4.2019

Endoscopy 2019; 51: E204

(c) Georg Thieme Verlag KG

Stuttgart · New York

ISSN 0013-726X
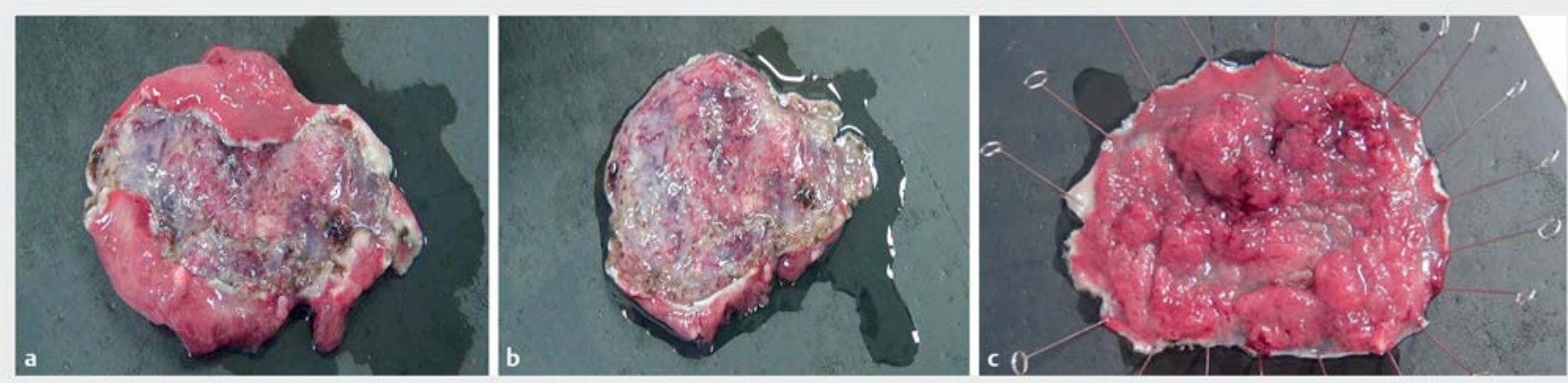

- Fig. 1 Photographs showing: a a resected specimen curling up after endoscopic submucosal dissection; $\mathbf{b}$ the specimen becoming relaxed after adrenaline is dropped onto it; $\mathbf{c}$ the resected specimen fixed mucosal side up onto a plate, which is now easily achievable. 